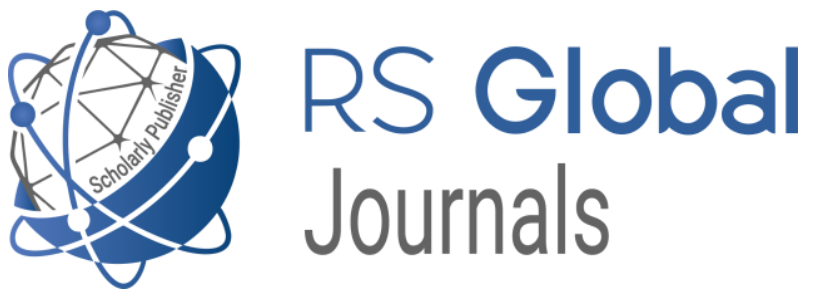

Scholarly Publisher

RS Global Sp. z O.O.

ISNI: 0000000484952390

Dolna 17, Warsaw, Poland 00-773

Tel: +48226022703

Email: editorial_office@rsglobal.pl

JOURNAL International Journal of Innovative Technologies in Social Science

p-ISSN $2544-9338$

e-ISSN

2544-9435

PUBLISHER

RS Global Sp. z O.O., Poland

ЭСТЕТИЧЕСКОЕ ПЕРЕЖИВАНИЕ КАК УСЛОВИЕ

ARTICLE TITLE
ХУДОЖЕСТВЕННОГО ВОСПРИЯТИЯ ЛИТЕРАТУРНОГО
НАЧА НА УРОКАХ ЛИТЕРАТУРНОГО ЧТЕНИЯ В

AUTHOR(S) Oборочану Виорика Ксенофонт

Oboroceanu V. X. (2020) Aesthetic Experience as a Condition of Artistic Perception of Literary Text in Literary Reading Lessons

ARTICLE INFO in Elementary School. International Journal of Innovative Technologies in Social Science. 7(28).

doi: $10.31435 /$ rsglobal_ijitss/30122020/7300

DOI

https://doi.org/10.31435/rsglobal_ijitss/30122020/7300

RECEIVED

30 October 2020

ACCEPTED

16 December 2020

PUBLISHED

21 December 2020

LICENSE

This work is licensed under a Creative Commons Attribution

4.0 International License.

(C) The author(s) 2020. This publication is an open access article. 


\title{
ЭСТЕТИЧЕСКОЕ ПЕРЕЖИВАНИЕ КАК УСЛОВИЕ ХУДОЖЕСТВЕННОГО ВОСПРИЯТИЯ ЛИТЕРАТУРНОГО ТЕКСТА НА УРОКАХ ЛИТЕРАТУРНОГО ЧТЕНИЯ В НАЧАЛЬНОЙ ШКОЛЕ
}

\author{
Оборочану Виорика Ксенофонт, \\ Кандидат педагогических наук, Тираспольский Государственный Университет, г. Кишинев, \\ Республика Молдова, ORCID ID: https://orcid.org/0000-0003-2591-0927
}

DOI: https://doi.org/10.31435/rsglobal_ijitss/30122020/7300

ARTICLE INFO

Received 30 October 2020 Accepted 16 December 2020

Published 21 December 2020

\section{KEYWORDS}

attitude, interpretive attitude, literary text, reading, learner, interest, understanding, perception, analysis.

\begin{abstract}
In the frame of literary texts, different values interact. This way, the interpretation of a literary text will include the pupil into various interpretative activities, thus forming its attitude.

Attitude is the understanding of the individual to assess an object, its symbol, or a certain aspect of the world. Whether positive or negative, attitude shows what position the person takes regarding the existing system of values, norms and principles in the society.

The literary work is by excellence an attitude generator. The text gives the opportunity to the pupil to assess new things, gradually passing and connecting previous ideas to the new ones. Meanwhile the reading process, the essential properties of the text and their relations with the new things are discovered. So, new ideas become intelligible for the pupil's understanding. The study of the literary text in the primary classes is performed in a complex manner. It provides not only comprehension, perception, analysis, interpretation and appreciation of reading, but also transfers literary-artistic and linguistic-communicative understanding into new situations, detached from everyday life with an individual approach.
\end{abstract}

Citation: Oboroceanu V. X. (2020) Aesthetic Experience as a Condition of Artistic Perception of Literary Text in Literary Reading Lessons in Elementary School. International Journal of Innovative Technologies in Social Science. 7(28). doi: 10.31435/rsglobal_ijitss/30122020/7300

Copyright: (C) 2020 Oboroceanu V. X. This is an open-access article distributed under the terms of the Creative Commons Attribution License (CC BY). The use, distribution or reproduction in other forums is permitted, provided the original author(s) or licensor are credited and that the original publication in this journal is cited, in accordance with accepted academic practice. No use, distribution or reproduction is permitted which does not comply with these terms.

Введение. В настоящее время очевидно, что традиционные механизмы изучения литературного произведения уже не удовлетворяют основных участников образовательного процесса - учащихся, что является одной из предпосылок, определивших выбор темы.

Другой предпосылкой можно считать проблему изучения литературного текста, потому что учащиеся оценивают это, рассказывая “содержание” или открывая тему, главную идею и художественные средства.

Учащимся предлагается воспроизвести тему литературного произведения, найти фрагмент, различать положительные и отрицательные персонажи, основные и второстепенные, охарактеризовать персонажей, исследовать действие через основные моменты. Более того, текст понимается только одним способом, допускается только одна его интерпретация, и в большинстве случаев это немного упрощенно.

Формирование читателя литературы через литературный текст - важный процесс становления человека как получателя литературных произведений и явлений, посредством деятельности восприятия, понимающей как фактическое восприятие художественного текста, так и действия по его интерпретации. 
Материалы и Методы. Понимание литературного текста - это сложный процесс выделения в нём структурных элементов и смысловых вех, сопровождающийся эмоциональным сопереживанием с автором, диалогичный по своей природе. Он позволяет читателю прийти к построению в сознании проекции текста с особым эмоциональным фоном, расширить знания о мире посредством анализа образной и идейной системы, выделить личностно значимые смыслы, обозначить границы единого с автором смыслового поля, а также получить эстетическое удовольствие. Сложность восприятия и понимания литературного текста школьниками обусловлена его особенностями: единством содержательной и языковой сторон текста, развёрнутой метафоричностью, наличием имплицитно представленных смыслов.

Литература в школе - это особый предмет, предлагающий такую модель отношений, с помощью которой изучаемое пропускается через себя, становится проекцией собственных мыслей. Читатель, знакомясь с художественным произведением, зачастую сам становится участником описываемых событий, отождествляет себя с героями, включается комплекс "СО”сочувствие, сопереживание, соучастие. Данный механизм имеет в основе своей перевод “языка художественных образов на язык логических понятий, когда читатель формулирует (интерпретирует) смысл и содержание прочитанного".

Литература, представленная в учебниках из начального цикла, претендует на то, чтобы приблизить учащихся к реальности, расширяет перспективы познания множества образований реальности. Чтение помогает читателю извлечь выгоду из способности удивлять, открывать для себя содержание и формы реальности, связывать их.

И. Шердян отмечает, что понимать литературу — это способность соотносить впечатления, переживания автора со своим жизненным опытом, это значит устанавливать связи не только с ранее известными, с известными представлениями, но и с эмоциями, чувствами. это побуждает их читать книгу. Контакт с художественным текстом не может быть прерван опытом и знаниями учащихся. Через аналогии и сравнения знания, полученные в результате чтения, сами по себе не останутся актом, а приведут к суждениям, эмоциям, обобщениям и определенности. [8, стр.214]

Текст составляет материальную основу эстетики, имеет художественную ценность, следовательно, это способ эстетического формирования ученика, развития его интеллектуального и культурного кругозора, и он является законченным продуктом, имеет начало и конец, образует автономную единицу и является наделен четко определенной внутренней организацией. Чтение означает встречу с текстом, то есть значение текста, которое никогда не заканчивается, оно возникает при каждой встрече с читателем / получателем и зависит от опыта и культуры человека. Текст является вехой в развитии коммуникативных навыков, подходит для функционального обследования.

Исследователи показывают, что в процессе интерпретации реципиент выстраивает собственную проекцию текста, которая наряду с изображением идеального художественного текста и механизмами сравнения идеального текста с предлагаемым включает в себя механизмы аксиологической интерпретации, позволяющие реципиенту дать ту или иную оценку.

Благодаря активной роли реципиента, вносящего в литературный текст свои представления о жизни и жизненных ценностях, становится возможным существование нескольких различных интерпретаций текста, что объясняется разным уровнем подготовки к пониманию и разными характеристиками языковых личностей. По интерпретации мы можем оценить степень и глубину понимания текста получателем.

Литературный текст - это текстовая конструкция согласно нормам литературы, со своими собственными целями и характеристиками, как язык, разработанный для того, чтобы вызвать эмоции у читателя.

Ю.М. Лотман, рассуждая о тексте и читателе, которые словно ищут взаимопонимания, говорит: «Текст ведёт себя как собеседник в диалоге: он перестраивается по образцу аудитории. А адресат отвечает ему тем же - использует свою информационную гибкость для перестройки, приближающей его к миру текста». На этом и базируется проблема интерпретации литературного текста. В связи с тем, что текст является знаковой системой, он подразумевает наличие истолкователя, то есть рассчитан на интерпретацию, а как следствие - на творческую активность. [11]

Рассуждая об интерпретации художественного произведения, методист В.Г. Маранцман говорит о том, что не сразу читатель приходит к свободе общения с писателем, не сразу анализируемый текст становится понятным.

Восприятие - психический процесс целостного отражения объектов в человеческом сознании, необходимый этап чувственного познания мира [15]. 
Восприятие в известной степени связано с переживанием, а понимание - c осмыслением. Человеку даны уникальные способности обнаруживать, различать и постигать содержание, смысл, значение явлений мира.

А.Б. Есин заметил, что с точки зрения семиотики этот процесс представляет собой один из случаев “экстралингвистического перевода, при котором совершенно неизбежны искажения” [10, с. 166].

Что стоит за этим словом “искажения”? Читатель смотрит на литературный текст через призму своего жизненного опыта, прошлых литературных знаний, эстетических предпочтений...

С середины XX в. целенаправленно изучается восприятие художественной литературы школьниками. Психолог О.И. Никифорова констатировала у учащихся младших классов «непосредственное эмоциональное восприятие текстов» и их «обдумывающее» восприятие [13].

Известный в детской литературе иллюстратор книг В.М. Конашевич называл ребенка “слишком последовательным реалистом”, требующим точного и ясного изображения предметов и лиц на рисунке. Такое интуитивное ощущение правды изображения способствует сопереживанию, а следовательно, вызывает эстетические эмоции [12, с. 27$].$

Под руководством учителя, при чтении ученик деконструирует текст, чтобы восстановить его значения, в то же время уроки литературы создают последовательно применяемую основу для получения текста. Мы можем начать с четырех отношений, которые создаются между читателем и текстом, идентифицировано Джудит Лангером:

- шагать снаружи внутрь: войти в мир текста;

- оказаться внутри и исследовать мир текста;

- сделать шаг назад и переосмыслить имеющиеся у нас данные;

- выйти из текстового мира и объективировать опыт.

По нашим наблюдениям, на первом этапе обучения младшие школьники обнаруживают такие типы восприятия, которые объясняются выделением какой-либо одной функции произведения:

- фактографическое: учащийся нацелен на выделение информации, фактов; обычно это дети со сниженной эмоциональностью и даже “эмоциональной глухотой” (В.А. Сухомлинский);

- положительно-эмоцииональное: ребенку нравится гедонистическая функция произведения, он получает удовольствие от слушания (тип, противоположный первому);

- фрагментарное: выборочное отношение к эпизодам (одни запоминаются детально, другие вообще не констатируются); дети со слабым общим речевым развитием;

- героико-ориентированное: учащийся проявляет интерес к героям (но не к автору и тексту), становится в позицию героя, содействует ему; обычно это дети, которые уже прошли первый этап ознакомления с детской литературой под руководством воспитателей детского сада или родителей.

Учитывая сложность текста как объекта восприятия и разнообразие существующих и создаваемых текстов, И. А. Зимняя вводит понятие “смысловое восприятие”, подчёркивая, что “понимание, как положительный результат процесса осмысления, органически входит в процесс речевого восприятия, представляя собой последовательность промежуточных решений или одномоментное решение типа инсайта в процессе осмысления" [16]. По мнению И. А. Зимней, восприятие и понимание образуют единый процесс, который представляет собой совокупность приёма (рецепции) речевого сообщения и его осмысления, результатирующегося в понимании (или непонимании). Данный процесс определяется учёным как смысловое восприятие, в общей формуле психологическая схема смыслового восприятия может быть представлена как система, характеризующаяся побуждающим, формирующим и реализующим уровнями.

Мы выделили следующие уровни восприятия литературных произведений в 4 классе:

- констатирующий (учащиеся называют тему, героев, сюжет, определяют “настроение” произведения);

- проблемно-тематический (учащиеся выделяют то, что их заинтересовало в содержании произведения);

- аналитический (учащиеся рассуждают об основных компонентах произведения, о причинно-следственных связях; большинство младших школьников при правильном обучении читательской самостоятельности выходят на этот уровень со 2 класса);

- предэстетический (учащиеся обращаются к позиции автора: замечают его отношение к событиям, героям, его словесные находки в пейзажах, портретах и т. д.; вступают в сотворчество; сопереживают; проявляют заинтересованное отношение к форме выражения мысли и чувств); 
- чувственно-интеллектуальный (условно эстетический) уровень, присущий обычно книголюбам, наиболее талантливым читателям, которые выдвигают гипотезы о развитии образа, высказывают литературные ассоциации, возникшие в памяти в связи с прочитанным, осуществляют сравнительный анализ «похожих» текстов для формулирования идейных выводов и тому подобное.

"Разговор с книгой" как упражнение в самостоятельном чтении-общении позволяет педагогу определить, на что направлено внимание учащихся при чтении, а что остается незамеченным, о чем они задумываются, а что для них неактуально.

Область чтения в начальных классах включает в себя следующие виды деятельности:

- чтение текста;

- запоминание и чтение текста;

- выразительное чтение текста;

- чтение по ролям диалогов из повествовательного / драматического текста;

- вопросительно-аналитическое чтение;

- адекватный прием лирического, эпического, драматического произведения;

- комментирует выразительный потенциал различных единиц художественного языка;

- мероприятия по расшифровке смыслов произведения;

- мероприятия по применению алгоритмов характеризации литературного персонажа;

- деятельность по интерпретации различных литературных произведений как жанрово-видовых, эстетических формул;

- творческое развитие литературных произведений.

Подходы к тексту касаются аспектов изучаемого текста (Что), которые будут рассматриваться и анализироваться в качестве приоритетных, а методы представляют способ, которым осуществляется дидактический подход (Как). Один и тот же подход может быть реализован разными методами. Таким образом, выбор метода или методов подхода, способов доступа к пониманию, анализу и интерпретации текста, естественно, предшествовать выбору методов обучения.

Умение задавать вопросы, соответствующие ситуации, и извлекать выгоду из текста допускает различные вопросы с информативным, познавательным и установочным потенциалом.

Анализ текста по традиционным вопросам (о чем написано? - тема, как автор относится к герою? - идея, каков жанр произведения? и т. д.) обязательно связан с формулированием ответов, в которых обнаруживается множество неточных представлений о содержании и форме текста. Только на основе сравнения вопросов и ответов можно объективно установить уровень понимания произведения со стороны учащегося.

Более сложный способ замера восприятия - ответы на вопросы учителя, которые задаются в определенной последовательности в отличие от детей и охватывают многие компоненты художественного произведения.

Единой схемы чтения, декодирования текста не существует. Следовательно, чтобы определить название, автор литературного произведения; рекомендует организацию семинара по чтению, на который приглашает учащегося:

- искать или предоставлять краткую информацию об авторе;

- разграничить идею художественного текста высказыванием «Текст учит меня ...»;

- аргументированно выразить собственное состояние после чтения с опорой на утверждение «Я жил чувствами ...»;

- аргументировать достоинства литературного персонажа в качестве предлога для самопознания и круга друзей, который у ученика возник благодаря идее «Я хотел бы друга в качестве персонажа ... потому что ...;

- подбирать новые слова, фразеологические выражения;

- присвоить художественному тексту максиму, пословицу.

Методы проведения вопросительно-толковательного чтения являются: Обзорный скелет; Журнал двойной записи; Ожидание; Быстрая прокрутка текста; Условия указаны заранее; Словесный организатор; Я знаю / хочу знать / узнал; Слепая рука.

В Обзорный скелет предусмотрено изложение рекомендованных работ, аргументация собственного мнения о прочитанных творениях. Учитель внимательно направит соответствующий “комментарий” через соответствующие вопросы. Учащихся могут попросить сформулировать свое мнение о соответствующей работе в письменной форме в соответствии с четко установленным планом: 1) автор, название книги; 2) о том, что рассказано в соответствующей книге, кратко излагая содержание; 3) какой эпизод или фрагмент особенно привлек его внимание и почему. 
В Журнал двойной записи маленький читатель записывает данные о прочитанных книгах, о самых красивых выражениях или отрывках, новых словах, цитатах. Эти заметки также будут очень полезны при написании сочинения или произнесении речи. В Персонализированном журнале чтения ученик записывает свои биографические данные об авторе (чтобы сделать первый шаг к индивидуальной документации, так необходимой студенту), название (как текста, так и книги, частью которой он является), предмет предельно короткие рассказы, похожие на план, разработанный идеями), портреты персонажей (краткие, по качествам, дефектам и характерным действиям), выражения со стилистической художественной ценностью (которые я могу использовать позже в композициях), рисунки со сценами чтения.

Литературная мандала адресована учащимся, которые решат, как будет выглядеть красочная история персонажа, представленная линиями и цветами. Междисциплинарность деятельности направлена на объединение литературы с математикой и искусством (использование фигур из геометрии и цветов в рисовании мандалы, чтобы рассказать историю персонажа), а дискуссии о принципах и моральных ценностях персонажа включают использование понятий гражданской культуры. недавно появился в классе.

Лист для чтения - это своего рода внешняя память прочитанного текста. Другими словами, непосредственная функция листа для чтения - это непосредственная и первичная материализация работы с текстом. Важная информация, а именно:

- Название и автор;

- Основные идеи;

- Соответствующие цитаты;

- Ключевые слова;

- Структура текста;

- Текстовые символы;

- Важные события в тексте;

- Личные впечатления.

Формирование статуса читателя в начальных классах также подразумевает развитие способности характеризовать литературных персонажей, и в этом случае мы считаем, что это доказывает его полезность и метод наблюдаемого взаимодействия (метод аквариума или аквариум), поскольку учеников начальной школы просят высказать свое мнение о персонажах обсуждаемых повествовательных текстов у них разное восприятие: одни внимательны к фактам, другие выходят за рамки поступков, совершенных персонажем, интуитивно догадываясь об их окончательности; некоторые рефлексивны, объективны, в то время как другие проявляют субъективность в оценке персонажа, позволяя управлять собой эмоциям, чувствам; одни принимают решения быстро, ища твердые элементы и игнорируя нюансы, другие же следуют элементам тонкости и медленнее делают выводы.

В каждом изучаемом литературном тексте после того, как учащиеся усвоили содержание и познакомились с персонажами, он драматизируется. Они выбирают своего персонажа, готовят свои реплики, каждый из которых предлагает что-то новое, интересное своим одноклассникам.

Выводы. В ходе аналитического исследования было обнаружено, что восприятия представляют собой вербальную, мимическую или жестовую экстернализацию положения / состояния учащегося, порождаемую образовательной средой и глобальными оценками определенных видов деятельности.

Изучение литературного текста в начальных классах осуществляется комплексно, что обеспечивает не только понимание, восприятие, анализ, интерпретацию и оценку прочитанного, но и передачу литературно-художественных и лингвистико-коммуникативных приобретений в новых ситуациях, оторванных от повседневной жизни. день и к ним можно обратиться независимо в индивидуальном порядке

Модернизация образовательного процесса в целом и формирование интерпретативных отношениях способствует развитию критического мышления, в частности, и может быть достигнута как путем применения в процессе интерпретации литературного произведения новых методов, рабочих процедур и их обогащения. старый, с новыми возможностями для организации и передачи информации. Конечно, из множества методов преподаватель выберет те, которые помогут учащимся легче расшифровать значения художественного текста как генератора, усилителя для развития критического мышления [14].

Отношение ученика к учебе является результатом воспитательного воздействия на него при помощи литературных текстов. Важно рассматривать обучение как непрерывный поток 
идей, информации и опыта, основанный на опыте интерпретации литературного текста. Помогая учащимся проникнуть в него, глубоко проанализировать, почувствовать связь идей и концепций, сопоставление восприятия текста с реальным миром способствует развитию критического мышления. Постепенно тексты являются основой критического анализа, что приводит к поиску решений в определенных обстоятельствах [9].

Опираясь на исследования и мнения исследователей, мы заключаем что, литературный текст значительно повысил уровень сформированности интерпретативных отношений учащихся экспериментальной группы и существенно улучшил мнение испытуемых о художественном тексте, повысил интерес к чтению художественных текстов.

Начальная школа, в отличие от других ступеней непрерывного образования, имеет условия наиболее тщательно заниматься формированием читателя, полноценно воспринимающего произведения детской литературы и доступные по возрастным показателям психологического развития тексты общей литературы и фольклора. Тревоги родителей, педагогов, социологов, философов по поводу неспособности общества обратить детей к чтению представляются нам разрешимыми.

В школе нужно стремиться не столько к научному, сколько к эстетическому освоению предмета, развивая творческие способности учащихся и их умения выражать в “речевом действии" свой литературный отклик.

Отношение ученика к литературному тексту проявляется в том, что он делится своим мнением относительно данного текста, поступков персонажа, сообщения, передаваемого прочитанным текстом, что способствует гармоничному развитию личности ученика, его активному вовлечению в учебный процесс и развитию взаимное доверие и поощряет обмен идеями.

Изучив методику обучения литературному чтению и правильно применяя ее в практике, можно добиться в начальной школе успешных результатов. Понимание и интерпретация текстов пробуждают позитивное отношение к общению и уверенность в своих навыках говорения и слушания, развивают интерес к общению, развивают позитивное отношение к личному развитию, стимулируют автономное, рефлексивное и критическое мышление.

\section{ЛИТЕРАТУРА}

1. Ghicov, A., Textul didactic şi abordarea lui din perspectiva realităţii de facto. În: Revista Intertext. Nr. 34(31) 2014. pp.161-167. ULIM. ISSN 1857-3711. CZU: 37.02

2. Golubiţchi, S., Aspecte didactice ale studierii textului literar în clasele primare. În: Materialele Conferinţei Ştiinţifice Internaţionale consacrate aniversării a 75 de ani de activitate:ISTORIE, PERFORMANȚE, PERSONALITĂȚI,20-21 octombrie 2016. Chișinău: IȘE .p.145-147. CZU 37.0:001.32(082)=135.1=161.1 I-57.

3. Oboroceanu, V ., Textul literar - factor reper în formarea atitudinilor interpretative. În: Revista Studia Universitatis (Seria Ştiinţe ale Educaţiei), Nr. 9 (129) / 2019 pp. 178-182. ISSN 1857-2103 / ISSNe 23451025 CZU: 37.036:801.73.

4. Oboroceanu, V., Atitudini interpretative în opera literară, Acta et Commentationes, Sciences of Education,nr.1(15)2019 ISSN 1857-0623 p.143-148 E-ISSN 2587-3636, CZU:37.016:81/82.135.1

5. Oboroceanu, V., Constante și variabile istorice ale conceptului de atitudine. În: Materialele conferinței republicane a cadrelor didactice,28-29 Februarie 2020. Vol.IV Educație preșcolară și primară. Chișinău: UST. 2020. 311p. pp.238-243 ISBN 978- 9975-76-301-1

6. Pânişoară, I.-O., Manolescu, M. Pedagogia învăţământului primar și preșcolar. Iași: Polirom. Vol. I , 2019. 688p. ISBN 978-973-46-7877-8.

7. Pânişoară, I.-O. , Manolescu, M. Pedagogia învățământului primar și preșcolar. Iași: Polirom. Vol. II, 2019. 440 p. ISBN 978-973-46-7878-5.

8. ŞERDEAN, I. Didactica limbii şi literaturii române în învăţământul primar. Bucureşti: Corint. 2008. 320 p. ISBN 978-973-135-233-6., стр.214

9. Голубицки, С., Оборочану, В. Интерпретация литературного текста как средство развития у учащихся критического мышиления. Материалы ХІІІ Международной научно-практической конференции: «Высшая школа: опыт, проблемы, перспективы», Москва: РУДН,02-03 апреля 2020г. Часть 2, 429c.c.217-221

10. Есин А.Б., Принципы и приемы анализа литературного произведения: Учебное пособие. - М.: Флинта, Наука,1998., с. 166.

11. Лотман, Ю.М., Анализ поэтического текста: Структура стиха. Издательство: Просвещение. 1972

12. Методика обучения литературе в начальной школе / под ред. М.П. Воюшиной. Москва, 2010, с. 27.

13. Никифорова О.И., Восприятие художественной литературы икольниками. Москва, 1982.

14. Оборочану, В., Голубицки С., Интерпретационные отношения -усилитель критического мышления. Вестник Международного научного центра «СОЦИУМ 2035» 2020. Т. 1. № 1. С. 98-105. ISSN 2687-0762

15. Психология: словарь / под общ. ред. А.В. Петровского, М.Г. Ярошевского. М., 1990.

16. Зимняя, И. А., Смысловое восприятие речевого сообщения. Москва, 1976. 